\title{
Phase sequences in balanced recurrent networks
}

\author{
Nikolay Chenkov ${ }^{1,2^{*}}$, Henning Sprekeler ${ }^{1,2}$, Richard Kempter ${ }^{1,2}$ \\ From Twenty Second Annual Computational Neuroscience Meeting: CNS*2013 \\ Paris, France. 13-18 July 2013
}

Electrophysiological recordings suggest that cortical circuits operate in a regime where the excitatory and inhibitory currents received by individual neurons are highly correlated in both time and stimulus selectivity. For such balanced input, neurons are activated by fluctuations in the input and tend to fire asynchronously and at irregular time intervals, a regime known as asynchronous irregular state.

However, transient synchronization and precise sequential firing has been observed during certain perceptual tasks or behavioral states. The neural mechanism behind these activity patterns has not yet been resolved. Here we address the problem by modeling a phase sequence embedded into a random recurrent network with sparse connectivity $p_{\text {rand }}$. The phase sequence as originally proposed by Donald Hebb [1] is a series of activity of cell assemblies connected in a feed-forward fashion. In our model, neurons representing one assembly are connected with recurrent probability $\mathrm{p}_{\mathrm{rc}}>\mathrm{p}_{\mathrm{rand}}$ while neurons in subsequent assemblies are connected with feed-forward probability $\mathrm{p}_{\mathrm{ff}}>\mathrm{p}_{\mathrm{pand}}$. Each assembly has a corresponding inhibitory subpopulation to which it is recurrently connected with probability $\mathrm{p}_{\mathrm{rc}}$ (see Figure 1A). Additionally, we apply an inhibitory plasticity rule that balances excitation and inhibition [2]. The role of such inhibition is twofold: it maintains asynchronous irregular firing of the excitatory population, and it enhances the response of an excitatory assembly through balanced amplification [3]. In the extreme case of no recurrent connectivity $\left(\mathrm{p}_{\mathrm{rc}}=0\right)$, the network resembles a synfire chain: a feed-forward network with convergent-divergent connections between subsequent groups of neurons [4].

In contrast to synfire chain models, the balanced recurrent network dramatically reduces the connection probability $\mathrm{p}_{\mathrm{ff}}$ that is required for the propagation of activity (Figure 1B). Simulations reveal a range of parameters in which asynchronous irregular spiking coexists with reliable activation and propagation of synchronous waves.


Figure $1 \mathrm{~A}$. Schematic of network connectivity between excitatory (E) and inhibitory (I) groups; B. Raster plots of 5,000 excitatory neurons representing ten assemblies, each of size 500 neurons during a phase sequence $(\operatorname{prc}=0.06$, pff $=0.06$, prand $=0.01$ ).

\footnotetext{
* Correspondence: nikolay.chenkov@bccn-berlin.de

${ }^{1}$ Institute for Theoretical Biology, Humboldt-Universität zu Berlin, Berlin,

Germany

Full list of author information is available at the end of the article
}

(C) 2013 Chenkov et al; licensee BioMed Central Ltd. This is an Open Access article distributed under the terms of the Creative Commons Attribution License (http://creativecommons.org/licenses/by/2.0), which permits unrestricted use, distribution, and reproduction in any medium, provided the original work is properly cited. 


\section{Acknowledgements}

Supported by BMBF grants no. 01GQ1001A and 01GQ1201.

\section{Author details}

'Institute for Theoretical Biology, Humboldt-Universität zu Berlin, Berlin, Germany. ${ }^{2}$ Bernstein Center for Computational Neuroscience Berlin, Germany.

Published: 8 July 2013

\section{References}

1. Hebb DO: The Organization of Behavior: A Neuropsychological Theory. New York: Wiley 1949.

2. Vogels TP, Sprekeler H, Zenke F, Clopath C, Gerstner W: Inhibitory plasticity balances excitation and inhibition in sensory pathways and memory networks. Science 2011, 334:1569-1573.

3. Murphy BK, Miller KD: Balanced amplification: a new mechanism of selective amplification of neural activity patterns. Neuron 2009, 61:635-648.

4. Diesmann M, Gewaltig MO, Aertsen A: Stable propagation of synchronous spiking in cortical neural networks. Nature 1999, 402:529-533.

doi:10.1186/1471-2202-14-S1-P207

Cite this article as: Chenkov et al.: Phase sequences in balanced

recurrent networks. BMC Neuroscience 2013 14(Suppl 1):P207.

\section{Submit your next manuscript to BioMed Central} and take full advantage of:

- Convenient online submission

- Thorough peer review

- No space constraints or color figure charges

- Immediate publication on acceptance

- Inclusion in PubMed, CAS, Scopus and Google Scholar

- Research which is freely available for redistribution

Submit your manuscript at www.biomedcentral.com/submit 